\title{
Mortality of slate workers in north Wales
}

\author{
P D OLDHAM, ${ }^{1}$ CAROL BEVAN,${ }^{2}$ P C ELWOOD, ${ }^{1}$ AND N G HODGES ${ }^{2}$ \\ From the MRC Epidemiology Unit (South Wales), ${ }^{1}$ Cardiff CF2 3AS, the former MRC Pneumonconiosis \\ Unit, ${ }^{2}$ Llandough Hospital, Penarth, S Glam, and Gwynedd Health Authority, ${ }^{3}$ Bangor, Gwynedd
}

ABSTRACT In a study in 1975 of the mortality experienced over six years by two groups of men one group had been exposed to slate dust and the other had had no previous exposure to dust. In non-smokers there was no material excess mortality associated with past exposure to dust but in smokers there was a pronounced $(26 \%)$ excess. In the slate workers the risk for smokers was on average $76 \%$ greater than for non-smokers, and increased with severity of pneumoconiosis; in those who had not been exposed to dust the risk was $50 \%$ greater for smokers than non-smokers. In ex-smokers among those who had been exposed to slate dust the risk of death was higher in those with the lower lung function initially. No such association was detected in the other groups.

The results of a survey of slate workers and other residents in north Wales in 1975 have been given by Glover et al. ${ }^{1}$ That study was mounted because it had been found that there was an excessive proportion of respiratory deaths in slate workers, not including deaths from pneumoconiosis, compared with others in previous years. A high prevalence of disabling pneumoconiosis was discovered. We now report mortality in a cohort of slate workers and in subjects who had not been exposed to slate or any other industrial dust.

\section{Method}

In the original survey in $1975,{ }^{1} 725$ men had been identified who had been exposed to slate but not to any other industrial dust. Another group of 530 men had never been exposed to any industrial dust. In what follows these are referred to as slate workers and controls.

By courtesy of the Office of Population Censuses and Surveys the deaths of any of these 1255 men were notified to us, together with the date and a copy of the medical certificate of cause of death. The deaths occurred during the period of changeover from the 8 th to the 9th revision of the International Classification of Causes of Death, so deaths occurring after the change were recoded as necessary so that all causes were in accordance with the 8th revision.

Notification of deaths is continuing, but in the present paper an analysis is presented of the mortality experienced up to 31 July 1981, a period of about six years. Because the survey continued over a period of

Accepted 27 January 1986 several months the data available consisted of age at date of interview in 1975, the number of days from interview until death or 31 July 1981, smoking habits, radiological score derived from the ILO radiological classification of the pneumoconiosis by the method of Oldham, ${ }^{2}$ anthropometric data, forced expiratory volume in one second $\left(\mathrm{FEV}_{1}\right)$, and forced vital capacity (FVC), all at date of interview. Men were grouped by smoking at the time of the 1975 survey: nonsmokers had never smoked as much as one cigarette a day for a year: ex-smokers had smoked cigarettes in the past but had not smoked for at least the past three months. A group of men who smoked a pipe but no other form of tobacco were also identified. No men smoked cigars without also smoking cigarettes.

To allow for the variation of risk of death with age (which ranged from 16 to 94) and with period of observation (which varied from 2206 to 2271 days) as well as with the factors of interest (lung function and radiological score), it was supposed that each man had a characteristic risk of dying, a function of his characteristics at the time of interview, which could be taken as remaining constant over the six years of follow up. A simple linear function was assumed, and this was set equal to the logarithm of the assumed constant risk. Thus, in its most general form, we assume for a man in a particular smoking group a constant risk $\lambda$ of dying each day, where $\log _{e} \lambda$ is a constant plus a multiple of his age, a multiple of his $\mathrm{FEV}_{1}$, a multiple of his radiological score, and so on:

$$
\log _{e} \lambda=a+b_{1} x_{1}+b_{2} x_{2}+\ldots
$$

On this basis the risk of an individual being dead by time $t$ is $1-e^{-\lambda t}$. The constants were estimated by the method of maximum likelihood. 
Results

Table 1 shows the numbers of men for whom data is available. All the data necessary to explore the role of

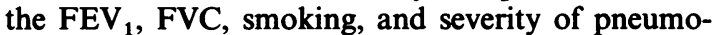
coniosis in determining the risk of death were available for $89 \%$ of the slate workers. Among the controls $87 \%$ had complete information but of those who died only $74 \%$ were completely documented.

Table 2 shows the age distributions of the two groups and of the 202 deaths. The unusual age distribution of the control subjects is a consequence of the sampling strategy in the original survey. ${ }^{1}$ Figure 1 shows the death rates by age, and clearly the groups do not differ appreciably, although the rates in the slate workers are never less than those of the controls between the ages of 40 and 60 .

Table 3 shows the 202 deaths grouped by cause, and again there are no important differences between the two groups. The small excess in proportion dying in the slate workers $(17.8 \%$ compared with $13.8 \%$ in the controls) is not eliminated if the eight deaths attributed to pneumoconiosis are removed. The numbers of deaths expected on a 129:73 partition are shown in brackets, and no cause shows pronounced

Table 1 Numbers of subjects for whom data is available

\begin{tabular}{lrr}
\hline Slate workers & \\
Complete data: & 647 \\
$\quad$ Lung function missing & 72 & \\
$\quad$ Height missing & 57 & \\
Smoking information missing & 3 & \\
$\quad X$ ray score missing & 52 & 78 \\
Partial data & & 725 \\
$\quad$ All slate workers & & \\
Controls & & 466 \\
Complete data: & 61 & \\
$\quad$ Lung function missing & 57 & \\
$\quad$ Height missing & 3 & 64 \\
Smoking information missing & & 530 \\
$\quad$ All controls & & \\
\hline
\end{tabular}

Table 2 Age distributions of slate workers and of controls. (Numbers of deaths in parentheses)

\begin{tabular}{lcc}
\hline Age (years) & Slate workers & Controls \\
\hline $15-$ & $71(-)$ & $20(-)$ \\
$25-$ & $108(1)$ & $80(-)$ \\
$35-$ & $105(5)$ & $117(2)$ \\
$45-$ & $137(14)$ & $136(10)$ \\
$55-$ & $161(38)$ & $79(12)$ \\
$65-$ & $111(45)$ & $79(34)$ \\
$75-$ & $27(21)$ & $18(14)$ \\
$85-$ & $5(5)$ & $1(1)$ \\
$95-$ & $-725(129)$ & $530(73)$ \\
All ages & 725 & -10 \\
\hline
\end{tabular}

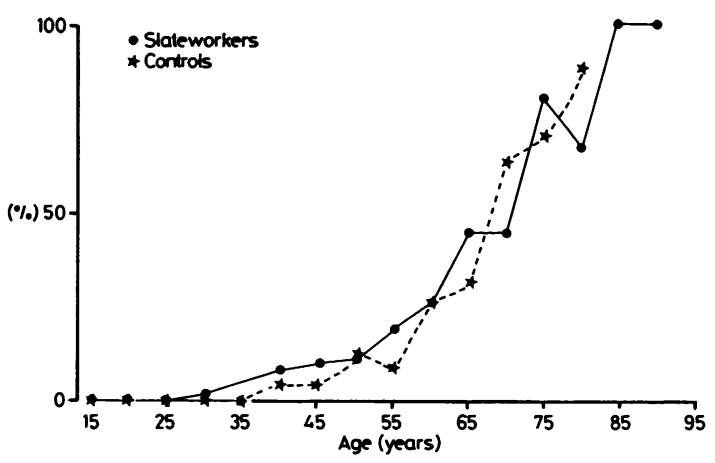

Fig 1 Proportion dead in slate workers and controls.

disproportionality. The 11 miscellaneous deaths comprised two from diseases of the nervous system, one from diabetes, three from "senility," and five from violence.

The smoking habits of the men could clearly be relevant to their mortality. Table 4 shows how they were distributed. There were six men whose smoking habits were not known, three slate workers who all survived, and three controls of whom one died. The 59 pure pipe smokers were too few to be treated separately: 10 of the 30 slate workers had died, four of the 29 non-dusty. The remaining six classes are all sufficiently numerous to be treated individually.

The linear regressions of $\log _{e} \lambda$ on age are listed in table 5. The more negative the constant the lower the risk of death. The age coefficients are all similar except that for ex-smokers in the slate workers, which is far smaller than the others. Excluding this group, a common age coefficient of $0.1030 \pm 0.0070$ could be fitted, the constants then changing slightly as shown in the second part of table 5. A likelihood analysis indicates that there is no significant loss of goodness

Table 3 Distribution of deaths by certified cause. (Deaths expected on a proportional basis shown in parentheses)

\begin{tabular}{lcc}
\hline Cause & Slate workers & Controls \\
\hline Cancer & $36(31 \cdot 9)$ & $14(18 \cdot 1)$ \\
Cardiovascular & $61(65 \cdot 1)$ & $41(36 \cdot 9)$ \\
Respiratory: & $4(3 \cdot 2)$ & $1(1 \cdot 8)$ \\
$\quad$ Tuberculosis & $7(4 \cdot 5)$ & $-(2 \cdot 5)$ \\
Pneumoconiosis & $1(0 \cdot 6)$ & $-(0 \cdot 4)$ \\
Both above & $1(1 \cdot 3)$ & $1(0 \cdot 7)$ \\
Interstitial fibrosis & $10(12 \cdot 1)$ & $9(6 \cdot 9)$ \\
Other & $3(3 \cdot 2)$ & $2(1 \cdot 8)$ \\
Gastrointestinal & $6(7 \cdot 0)$ & $5(4 \cdot 0)$ \\
Miscellaneous & $129(129 \cdot 0)$ & $73(73 \cdot 0)$ \\
All causes & & \\
\hline
\end{tabular}


Table 4 Age distributions by smoking habits. (Numbers of deaths in parentheses)

\begin{tabular}{|c|c|c|c|c|c|}
\hline Age (years) & Nil & Cigarette & Ex-smoker & Pipe & Unknown \\
\hline $\begin{array}{l}\text { Slate workers } \\
15- \\
25- \\
35- \\
45- \\
55- \\
65- \\
75- \\
85-\end{array}$ & $\begin{array}{l}24 \\
15 \\
10 \\
12 \\
22(1) \\
17(7) \\
4(3) \\
3(3)\end{array}$ & $\begin{array}{l}35 \\
71(1) \\
76(5) \\
97(9) \\
76(21) \\
47(23) \\
11(10) \\
-\end{array}$ & $\begin{array}{l}12 \\
18 \\
17 \\
22(5) \\
57(15) \\
36(10) \\
9(5) \\
1(1)\end{array}$ & $\begin{array}{l}-3 \\
2 \\
5 \\
5(1) \\
11(5) \\
3(3) \\
1(1)\end{array}$ & $\begin{array}{l}\frac{1}{1} \\
\frac{1}{-} \\
-\end{array}$ \\
\hline Totals & $107(14)$ & $413(69)$ & $172(36)$ & $30(10)$ & 3 \\
\hline $\begin{array}{l}\text { Controls } \\
15- \\
25- \\
35- \\
45- \\
55- \\
65- \\
75- \\
85-\end{array}$ & $\begin{array}{r}6 \\
18 \\
27 \\
16 \\
11(2) \\
9(2) \\
3(3) \\
1(1)\end{array}$ & $\begin{array}{l}11 \\
45 \\
56(2) \\
85(9) \\
40(4) \\
38(19) \\
10(8) \\
-\quad\end{array}$ & $\begin{array}{c}3 \\
16 \\
27 \\
28(1) \\
19(4) \\
25(11) \\
4(2) \\
-\quad\end{array}$ & $\begin{array}{l}-1 \\
7 \\
7 \\
6(1) \\
7(2) \\
1(1) \\
-\end{array}$ & $\begin{array}{l}- \\
- \\
\overline{3}(1) \\
- \\
-\end{array}$ \\
\hline Totals & 91 (8) & 285 (42) & $122(18)$ & 29 (4) & $3(1)$ \\
\hline
\end{tabular}

of fit by using a single, average age coefficient:

Separate constants and age coefficients

Separate constants but a single age coefficient

$-1450 \cdot 409$
Difference $\quad 1.255$

$\chi^{2}(4 \mathrm{df})=$ twice difference $=2.51,0.70>\mathrm{p}>0.50$

The regression lines for $\log _{e} \lambda$ are now almost identical for non-smokers in both the slate and control groups. Smokers in the slate workers had the highest overall risk (the least negative constant), then came smokers in the control group, then ex-smokers in the controls, then the two non-smoking groups. The standard

Table 5 Dependence of risk of death on age, by smoking group. $\left(\log _{\mathrm{e}} \lambda=a+\right.$ b.age $)$

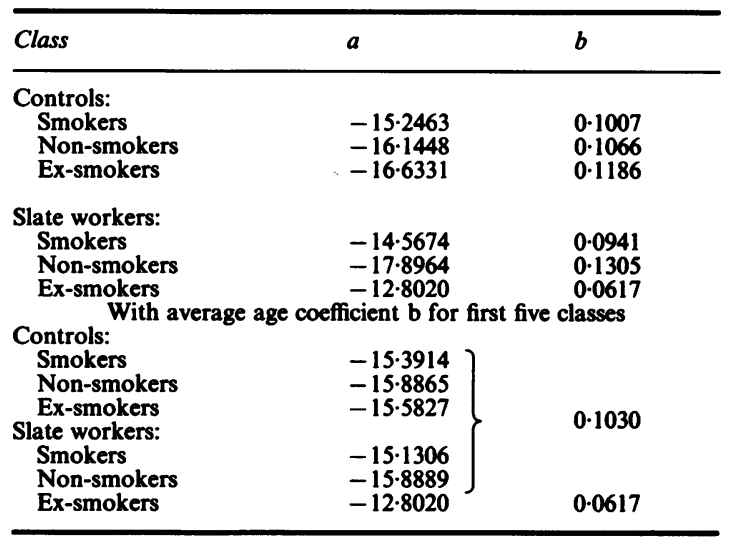

errors of the constants are too large for many pairwise comparisons to be significant, but their total variation from group to group is significant:

Separate constants and a single

age coefficient

Log likelihood

One single constant

$$
-1450 \cdot 409
$$

$-1455 \cdot 885$

Difference $5 \cdot 476$

$\chi^{2}(4 \mathrm{df})=$ twice difference $=10.952,0.05>\mathrm{p}>0.02$

Figure 2 shows the death rates by year of age resulting from this analysis. The ordinate is the value of $1-\exp (-365 \lambda)$ for each group expressed as a percentage. The exceptional group of ex-smokers among the slate workers is marked by its higher death rate up to age 60 increasing less rapidly with age. The fit of the data is illustrated in table 6; there are no obvious discrepancies except for a slight underestimation of the number of deaths. This seems to be

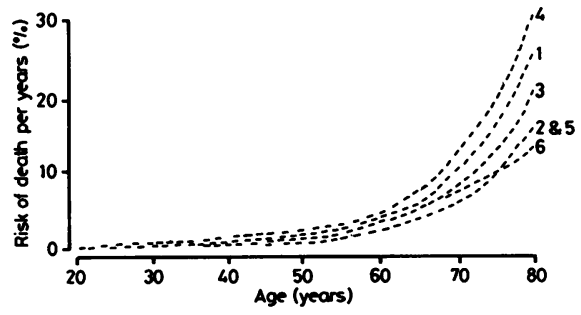

Fig 2 Risk of death by age and smoking group in slate workers and controls ( $1=$ control who smoked; 2 = control non-smokers; 3 = control ex-smokers; $4=$ slate workers who smoked; 5 = slate workers who did not smoke; 6 = slate workers ex-smokers). 
Table 6 Distributions of observed deaths by age, and numbers of predicted deaths by the regressions in table 5

\begin{tabular}{|c|c|c|c|c|}
\hline \multirow[t]{2}{*}{ Age group } & \multicolumn{2}{|c|}{ Slate workers } & \multicolumn{2}{|l|}{ Controls } \\
\hline & Observed & Predicted & Observed & Predicted \\
\hline \multirow[t]{2}{*}{$\begin{array}{l}15- \\
25- \\
35- \\
45- \\
55- \\
65- \\
75- \\
85-\end{array}$} & $\begin{array}{r}0 \\
1 \\
5 \\
14 \\
37 \\
40 \\
18 \\
4\end{array}$ & $\begin{array}{r}0.5 \\
1.7 \\
4.2 \\
12.5 \\
33.7 \\
41.4 \\
16.1 \\
3.5\end{array}$ & $\begin{array}{r}0 \\
0 \\
2 \\
10 \\
10 \\
32 \\
13 \\
1\end{array}$ & $\begin{array}{r}0.1 \\
0.8 \\
2.6 \\
8.3 \\
11.3 \\
28.1 \\
12.6 \\
1.0\end{array}$ \\
\hline & 119 & 113.0 & 68 & $64 \cdot 8$ \\
\hline \multirow[t]{2}{*}{$\begin{array}{l}\text { Pure pipe smokers } \\
\text { Unknown smoking }\end{array}$} & $\begin{array}{r}10 \\
0\end{array}$ & - & $\begin{array}{l}4 \\
1\end{array}$ & - \\
\hline & 129 & & 73 & \\
\hline
\end{tabular}

Table 7 Regression coefficients of risk of death in the controls on age and lung function (standardised to a common mean height)

\begin{tabular}{|c|c|c|c|c|}
\hline & \multicolumn{2}{|l|}{$F E V$} & \multicolumn{2}{|l|}{$F V C$} \\
\hline & Estimate & $S E$ & Estimate & $S E$ \\
\hline $\begin{array}{l}\text { Smokers: } \\
\text { Age } \\
\text { Lung function }\end{array}$ & $\begin{array}{l}+0.090 \\
-0.155\end{array}$ & $\begin{array}{l} \pm 0.017^{*} \\
\pm 0.246\end{array}$ & $\begin{array}{l}+0.093 \\
-0.093\end{array}$ & $\begin{array}{l} \pm 0.020^{*} \\
\pm 0.262\end{array}$ \\
\hline $\begin{array}{l}\text { Ex-smokers: } \\
\text { Age } \\
\text { Lung function }\end{array}$ & $\begin{array}{l}+0.095 \\
-0.392\end{array}$ & $\begin{array}{l} \pm 0.029^{*} \\
\pm 0.261\end{array}$ & $\begin{array}{l}+0.092 \\
-0.443\end{array}$ & $\begin{array}{l} \pm 0.029 * \\
\pm 0.278\end{array}$ \\
\hline $\begin{array}{l}\text { Non-smokers: } \\
\text { Age } \\
\text { Lung function }\end{array}$ & $\begin{array}{l}+0.149 \\
+0.080\end{array}$ & $\begin{array}{l} \pm 0.074^{*} \\
\pm 0.507\end{array}$ & $\begin{array}{l}+0.174 \\
+0.478\end{array}$ & $\begin{array}{l} \pm 0.081^{*} \\
\pm 0.977\end{array}$ \\
\hline
\end{tabular}

*Statistically significant at $p<0.05$.

Table 8 Regression coefficients of risk of death in slate workers on age, $x$ ray score, and standardised lung function

\begin{tabular}{|c|c|c|c|c|}
\hline & \multicolumn{2}{|l|}{$F E V$} & \multicolumn{2}{|l|}{$F V C$} \\
\hline & Estimate & $S E$ & Estimate & $S E$ \\
\hline \multicolumn{5}{|l|}{ Smokers: } \\
\hline $\begin{array}{l}\text { Age } \\
X \text { ray } \\
\text { Lung function }\end{array}$ & $\begin{array}{l}+0.082 \\
+0.587 \\
-0.107\end{array}$ & $\begin{array}{l} \pm 0.015^{*} \\
\pm 0.171^{*} \\
\pm 0.237\end{array}$ & $\begin{array}{l}+0.083 \\
+0.595 \\
-0.067\end{array}$ & $\begin{array}{l} \pm 0.015^{*} \\
\pm 0.171^{*} \\
\pm 0.208\end{array}$ \\
\hline \multicolumn{5}{|l|}{ Ex-smokers: } \\
\hline $\begin{array}{l}\text { Age } \\
X \text { ray } \\
\text { Lung function }\end{array}$ & $\begin{array}{l}+0.031 \\
-0.042 \\
-0.981\end{array}$ & $\begin{array}{l} \pm 0.021 \\
\pm 0.240 \\
\pm 0.248^{*}\end{array}$ & $\begin{array}{l}+0.026 \\
-0.047 \\
-1.140\end{array}$ & $\begin{array}{l} \pm 0.020 \\
\pm 0.227 \\
\pm 0.219^{*}\end{array}$ \\
\hline \multirow{2}{*}{$\begin{array}{l}\text { Non-smokers: } \\
\text { Age } \\
X \text { ray } \\
\text { Lung function }\end{array}$} & & & & \\
\hline & $\begin{array}{l}+0.114 \\
+0.326 \\
-0.511\end{array}$ & $\begin{array}{l} \pm 0.038^{*} \\
\pm 0.361 \\
\pm 0.730\end{array}$ & $\begin{array}{l}+0.112 \\
+0.215 \\
-0.505\end{array}$ & $\begin{array}{l} \pm 0.036^{*} \\
\pm 0.411 \\
\pm 0.585\end{array}$ \\
\hline
\end{tabular}

*Statistically significant at $\mathrm{p}<0.05$.

the result of using a common slope for five classes; it is not present in the slate ex-smokers.

The other characteristics of the men known were their radiological scores and their lung function. The few abnormal radiographs among the control men were in many cases known to be caused by disease other than pneumoconiosis, and it was assumed that this was true in all cases. The dependence of mortality on FEV $_{1}$ and FVC was therefore explored. Both indices were standardised to a height of $1.7 \mathrm{~m}$ by dividing 
by the square of the man's height and multiplying by the square of 1.7 as recommended by Cole. ${ }^{3}$ There was no statistically significant dependence on mortality on either index, and the calculated regression coefficients for $\mathrm{FEV}_{1}$ and FVC were neither similar nor consistent with a real effect (table 7).

In the slate workers the results for both $\mathrm{FEV}_{1}$ and FVC were similar: in the non-smokers no significant effect on mortality or either lung function or radiological score, in smokers a significantly increased risk of death with increasing radiological score but no relation to lung function, and in ex-smokers no effect of radiological score but a pronounced dependence on lung function, rather more on FVC than on FEV 1 (table 8). Indeed the decline of lung function with age was such that there was no additional effect of age after lung function was allowed for.

\section{Discussion}

The first conclusion that appears from this study is the relatively small excess of mortality in men exposed to slate dust, compared with men from the same area who had not been exposed to dust. This is despite the fact that many showed considerable radiological evidence of pneumoconiosis and this had previously been found to be associated with a loss in lung function. ${ }^{1}$

Table 9 Numbers of observed deaths by smoking and exposure classes, and the numbers expected on the basis of the mortality rates of all 1255 men in five year age groups

\begin{tabular}{lcc}
\hline & Slate workers & Controls \\
\hline Non-smokers & $14(19 \cdot 8)$ & $8(10 \cdot 9)$ \\
Smokers & $69(56 \cdot 3)$ & $42(41 \cdot 2)$ \\
Ex-smokers & $36(38 \cdot 3)$ & $18(20 \cdot 4)$ \\
Pure pipe smokers & $10(9 \cdot 2)$ & $4(5 \cdot 2)$ \\
Unknown & $0(0 \cdot 2)$ & $1(0 \cdot 6)$ \\
& $129(123.7)$ & $73(78 \cdot 3)$ \\
\hline
\end{tabular}

As soon as cigarette smoking is allowed for, however, a different conclusion is suggested. In nonsmokers the excess risk of death in slate workers is no more than $0.25 \%$; in smokers it is $26 \%$ (the difference in $\log _{e} \lambda$, with a common age coefficient, is 15.39 15.13 or 0.26 ). In slate workers the risk for smokers is $76 \%$ greater than for non-smokers; in the controls $50 \%$ greater. These estimates have large standard errors but provide a good fit to the model assumed. Table 9 shows that effects of this type accord with the results; the death rates in five year age groups experienced by all 1255 men have been applied to the two occupational groups subdivided by smoking class to give expected numbers of deaths which may be compared with observed numbers, as in calculating age standardised mortality rates. The one conspicious feature is the excess mortality experienced in the smoking slate workers, which is balanced by deficiencies in non-smokers, both slate workers and controls. These relative rates confirm the appearance of an excess effect when smoking is combined with exposure to slate dust.

The radiological data on the severity of pneumoconiosis again pick out this group of smokers as the only one whose mortality increases significantly with pneumoconiosis score. In non-smokers and exsmokers it appears irrelevant. It must be remembered that in so far as the amount of pneumoconiosis tends to increase with age, it is only when mortality can be seen to occur at a rate increasing with the amount of pneumoconiosis in men of the same age that a joint effect may be detected. Rather than the smokers being in any way unusual, it may be solely that they are sufficiently numerous for such trends to show themselves. Table 10 shows distinct trends of mortality increasing with radiological score in men of the same age. Even in these 384 smokers with $x$ ray data the numbers in individual cells are small, and in the other smoking classes the numbers are less than half the size.

The lack of a relation between mortality and lung function except in another single group, this time the ex-smokers in the pure slate workers, again must be

Table 10 Distribution of deaths by age and $x$ ray score in the slate workers who smoked

\begin{tabular}{|c|c|c|c|c|c|c|c|}
\hline \multirow{2}{*}{$\begin{array}{l}\text { Age } \\
\text { group }\end{array}$} & \multicolumn{7}{|c|}{$X$ ray score } \\
\hline & Normal & $0.6-$ & 1.0 & $1.5-$ & $2 \cdot 0$ & $2 \cdot 5-$ & $3 \cdot 0$ \\
\hline $\begin{array}{l}15- \\
25- \\
35- \\
45- \\
55- \\
65- \\
75-\end{array}$ & $\begin{array}{l}30 \\
48 \\
39(2) \\
50(3) \\
24(6) \\
13(3) \\
4(3)\end{array}$ & $\begin{array}{c}3 \\
9 \\
17(1) \\
17(1) \\
12(4) \\
5 \\
1(1)\end{array}$ & $\begin{array}{c}1 \\
9 \\
12(1) \\
10(4) \\
16(2) \\
6(4) \\
2(2)\end{array}$ & $\begin{array}{l}-2 \\
4 \\
9 \\
7(2) \\
5(3) \\
3(3)\end{array}$ & $\begin{array}{l}\overline{-} \\
\overline{1}(1) \\
3 \\
2(1) \\
4(3) \\
1(1)\end{array}$ & $\begin{array}{l}\overline{-} \\
\bar{z} \\
6(1) \\
6(6)\end{array}$ & $\begin{array}{l}\bar{z} \\
\overline{-} \\
1(1) \\
\overline{2(2)}\end{array}$ \\
\hline Totals & 208 (17) & $64(7)$ & $56(13)$ & $30(8)$ & $11(6)$ & $12(9)$ & $3(3)$ \\
\hline
\end{tabular}




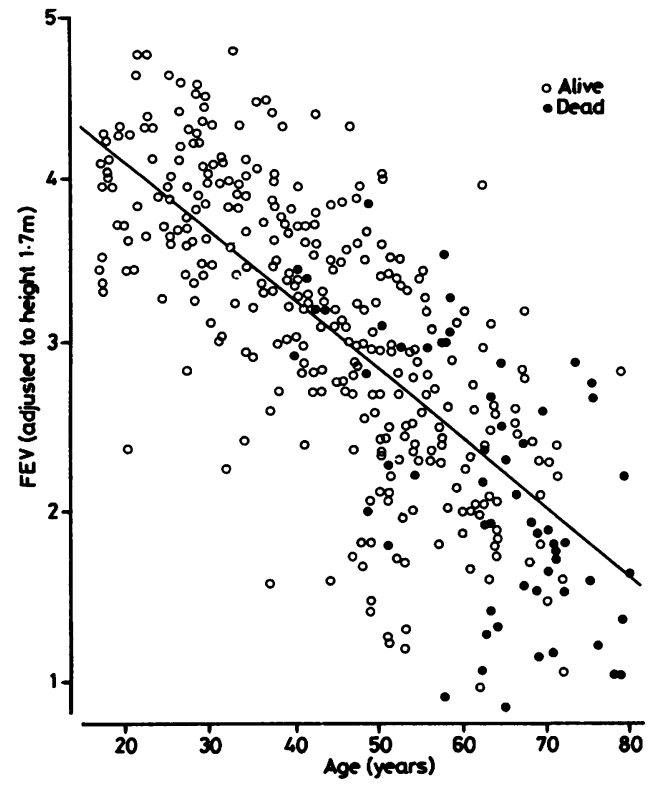

Fig $3 F E V$, by age in slate workers who smoked.

interpreted in the light of the fact that lung function declines on average with age, so that in so far as risk of death inevitably increases with age, loss of lung function will only be detected as a relevant factor if, among men of the same age, deaths occur to excess in those with reduced lung function. Figures 3 and 4 show the relation between $F E V_{1}$ and age in the slate workers, smokers, and ex-smokers respectively, and those who died are marked. In the smokers almost equal numbers of the deaths fall above and below the regression line giving average $F E V_{1}$ by year of age: in the ex-smokers there is a significant excess of deaths in men with below average FEV $_{1} \mathrm{~s}$

$\left(\chi_{c}^{2}=(20-8-1)^{2} / 28=4.32,0.05>p>0.02\right)$.

The significance of the dependence of mortality on lung function reflects this but its explanation remains obscure. The FEV 1 s of the smokers and ex-smokers are, age for age, similar, and there is little difference between those of the smokers who died and those who did not. On the other hand the $\mathrm{FEV}_{1} \mathrm{~s}$ of the exsmokers who died were between 300 and $500 \mathrm{ml}$ lower, and those of the survivors somewhat higher. It appears likely that, at the point when a smoker decides to become an ex-smoker, there is a dichotomy between those whose lung function improves or remains the same and those whose lung function continues to decline. How these types could be distinguished is not clear.

Peto et al have established a pronounced correlation between low FEV $_{1}$ and death from chronic obstructive pulmonary disease in 2718 men followed up for 20 to 25 years. ${ }^{4}$ It is not to be expected that in the present study, in which only 35 men died of any

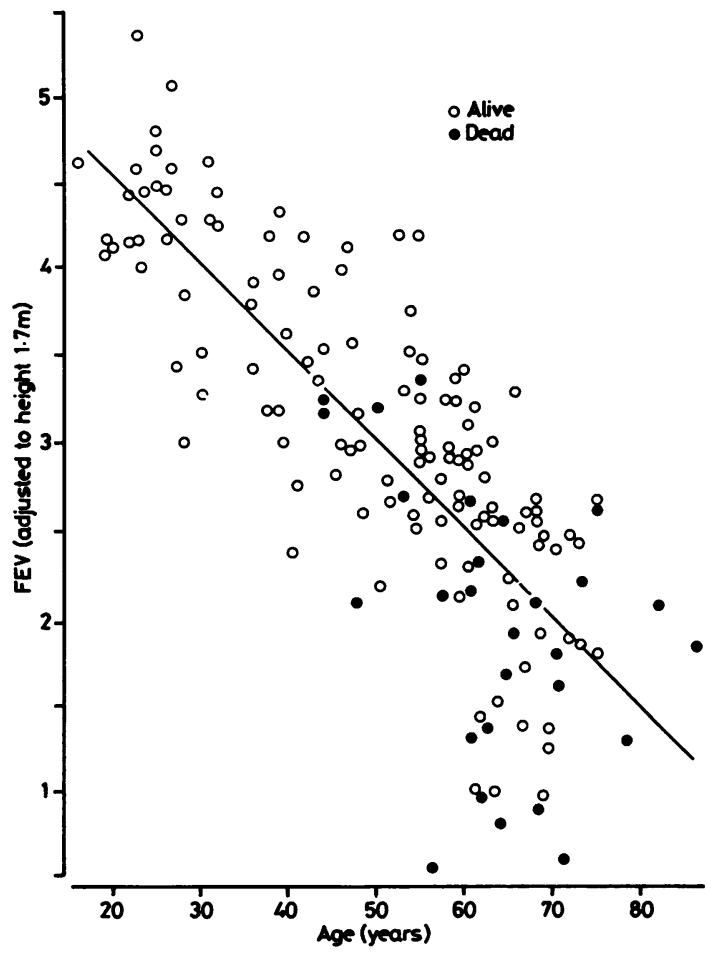

Fig $4 F E V_{1}$ by age in slate workers who were ex-smokers.

respiratory disease, such an effect would be detected, but it is slightly surprising that the role of $F E V_{1}$ in this study was so limited.

It remains to consider how the grounds for mounting the original survey, a considerable proportional excess of respiratory mortality in slate workers (excluding deaths attributed to pneumoconiosis), may be reconciled with the trifling excess now discovered. One obvious possibility is that the present proportion of smokers, $57 \%$ in slate workers in 1975 , is far less than it was in the ten years from 1962 to 1971 used to estimate the proportional mortality and the pronounced excess risk now discovered for the combination of exposure to slate dust and smoking produced the excess. There seems to be no clear way to explore this hypothesis.

\section{References}

${ }^{1}$ Glover JR, Bevan C, Cotes JE, et al. Effects of exposure to slate dust in North Wales. $\mathrm{Br} J$ Ind Med 1980;37:152-62.

${ }^{2}$ Oldham PD. Numerical scoring of radiological pneumoconiosis. In: Walton WH, ed. Inhaled particles III. Old Woking, Surrey: Unwin, 1971:621-30.

${ }^{3}$ Cole TJ. Linear and proportional regression models in the prediction of ventilatory function. Journal of the Royal Statistical Society Series A 1975;138:297-338.

${ }^{4}$ Peto R, Speizer FE, Cochrane AL, et al. The relevance in adults of airflow obstruction, but not of mucus hypersecretion, to mortality from chronic lung disease. Am Rev Respir Dis 1983;128:491-500. 